\title{
Wandering Away from Service Quality: Vagabond Boutique
}

\author{
Weronika Kucharska \\ LIM College \\ 216 E 45th St, New York, NY 10017, USA \\ Herbert Sherman \\ Long Island University-Brooklyn \\ Brooklyn, New York, USA
}

\begin{abstract}
This is an anthropological field-based instructional case written for students in an introductory fashion-marketing course, although it is also applicable to a foundation-marketing course in an undergraduate or graduate business program or a small business management course. The case centers around the detrimental impact that negative word of mouth (NWM) may have on a small business, and how such unfavorable publicity can be avoided. The case focuses on Katya, a sales associate at Vagabond Boutique (a small vintage clothing shop), and the poor sales service of her fellow employees that led to several negative Yelp reviews and thereby influenced the boutique's market positioning. The analysis that follows posited that had the owners of the boutique had more time to focus on the employee training, and then such negative promotion would not have come to fruition. The analysis focuses on three theories; internal marketing, service quality, as well as brand differentiation, and how such theories could be successfully implemented and in turn alleviate the poor sales service that tarnished the image of Vagabond Boutique.
\end{abstract}

Keywords: Retail, customer service, Yelp, negative word of mouth (NWM).

\section{Introduction}

Vagabond is the brainchild of Mary Clark and Megan Murphy. Megan and Mary met at a knitting class and bonded over their love of fashion and all things vintage, and decided to team up and open Vagabond Boutique. Both Mary and Megan have backgrounds in many aspects of design, including knitting, crochet, sewing, pattern making and more. Originally located in Cape May at the New Jersey Shore,the boutique grew up and found a place to call home in the Old City district of Center City Philadelphia, where it continues to thrive. The two set out to open a shop unlike anything that Philadelphia had seen before; a storefront that carried sought-after designer brands, along with soft knits created by Mary, and beautifully curated vintage pieces found by Megan. (See Appendix A, The Unique Interior of the Boutique)

Located on a cobblestone street in a historic section of Philadelphia, the boutique was incredibly successful and became widely known for its collection and creative spirit. Vagabond caters to creative women with an eclectic taste of all ages and incomes. Opened in the late 1990's, the boutique has not only survived, but also thrived for the past 20 years- a lifetime compared to a majority of the boutiques in the immediate area. The success and popularity of the boutique is showcased by being named Best Women's Boutique four years in a row by Philadelphia Magazine. They are located at 37 N. Third Street Philadelphia, PA 19106. Phone: 267-671-0737. Hours are Mon-Sat: 11am-7pm EST, Sun: 11am-5pm EST. (http://shopatvagabond.blogspot.com/, September 27, 2017)

The boutique is quite small and is primarily comprised of the owners, Megan and Mary, and two other employees. The culture at Vagabond is extremely lax and there is effectively no competition amongst the employees. This is because there are no commission-based incentives, as well as the exceptionally laidback attitude that is perpetuated within the boutique. For example, employees are allowed to write out their own paychecks at the end of the week. The owners, Megan and Mary, are rarely at the boutique and communicate with the employees primarily via text. There are no formal supervisors at the store or any sort of hierarchy among employees, with only the owners as absentee managers. See Appendix B, Vagabond Boutique Organizational Chart. 
Katya glanced at her phone to check the time - 11:20 am. She was supposed to be at Vagabond at 11:00 am to open up the shop but woke up late. Katya felt a sting of remorse at her chronic tardiness, but knew there would be no repercussions. As Katya finished up parallel parking in the tiny cobble-stoned street and rummaged through her bag for her key, she could see that there were a couple of customers waiting outside of the boutique. She quickly ran over to the boutique, apologized to the two women waiting outside, and made up an excuse that she was held up in traffic.

Around 12 o'clock, the second employee, Sarah, strolled in nonchalantly, wearing ripped jeans and a gorgeous silk vintage top. Katya quickly struck up a conversation with Sarah about which thrift shop she managed to find the top at, even though there were several customers in the shop. After a half hour of chatting, Sarah looked down at her phone to see that she had received a long text from one of the owners, Mary. "Uh oh," muttered Sarah. "What's wrong...?" Katya asked cautiously.

"Mary just texted me saying that we received another bad Yelp review. It seems that a customer arrived at our store at 11 AM several times and we were not open. Mary sent me the Yelp review - here, take a look."

Tried going several times with my wife. Each time the door was locked during store hours. The last time we went they put a sign reading "out to lunch" as we tried to open the door. They ignored us. Mind you, they open at $11 \mathrm{am}$. They were already out to lunch by 1:30. No store in NYC would do that. We're coming from out of town! Hopefully they can get it together.Jeff A., Jersey City, New Jersey (https://www.yelp.com/biz/vagabondphiladelphia, 10/16/17)

"She also said that a friend of hers came in here and was given attitude by one of the sales girls," Sarah answered. "Look what her friend wrote!"

The sales associates are so rude. I like some of their stuff but wow it is not worth dealing with the pretentious ladies who work there. They act like you are hassling them if you have a question.Nora F. Philadelphia, Pa. (https://www.yelp.com/biz/vagabond-philadelphia, 10/16/17)

Katya felt her stomach tie up in knots. This was one of the many bad Yelp reviews the store had received as of late and she knew this did not bode well for the image of Vagabond. "Oh no," muttered Katya. "Any idea who it was that gave the customer attitude?" "Nope, all Mary said was that it was a blond sales girl." Katya gulped ... she was blond and Sarah was a brown-haired.

As Sarah was saying this, Katya managed to glance over Sarah's shoulder to see that another text came in from Mary, and could see her name being mentioned as the sales girl in question. Katya's cheeks immediately turned red. How could Mary assume that she was the one at fault here even if she was a blond? Mary was never around to ensure that the boutique was being run smoothly, let alone to see how Katya interacted with the other customers. Katya could feel her eyes filling with tears as a customer walked over to ask Katya if there were any more of the Black Crane jumpsuits in a size small.

Katya quickly ran to the back to check for the client, as well as to hide her sudden anger at Mary. In the back room, amidst the chaos of vintage furniture pieces, and the overly cluttered boxes that housed the various clothing items, Katya knew very well that even if the jumpsuit was available, there was no way she would be able to find it in the vast mess. Katya peeked her head out of the back room and screamed to Sarah across the boutique "Hey Sarah! Any idea if we have any more of the Black Crane jumpsuit in size small?" "Hmm..." answered Sarah, as she was attempting to ring up a customer, "No I think I sold the last small one last week."

Sarah returned to ringing up the perplexed customer, as she tried to calculate the customer's total. The boutique was incredibly "old-school," in that there was no inventory system through which the employees could check what product they have in stock. All products were entered into a daily excel sheet that chronicled all of the items sold, and how much was made in sales each day. A huge innovation for the firm was the recent purchase of an iPad with the POS system, Square. This was bought simply for the ease of the credit card reader, which frustrated Katya as she knew that the iPad could be successfully utilized to enter all of their stock and therefore keep better control of their inventory. Yet, she knew that neither of the owners would ever agree to such a "radical" idea.

Katya strolled back over to her post behind the counter, passing by customers along the way and not bothering to ask a single customer if they needed help with anything. She then checked her phone and answered a text from her sister, all the while customers filtered in and out of the store, occasionally making a purchase. This time Sarah decided to be a little more proactive and checked out the Yelp website herself ... she was not happy with what she found. 
For Philly, this is a good boutique. I would rate the merchandise at 4 stars. They lose two for customer service. I have been in Vagabond several times and no matter how the sale reps are treated by me (I've done friendly and chatty; I've done indifferent and borderline rude), I get the same cold, dead response. If it's a sales tactic, it sucks. Will you be my friend if I buy this black crane dress? No? What if I add a Kathleen Whittaker earring? No?! I'll buy a pair!!!! Please smile!!!! Maybe none of them have teeth? Agnes. M. Collinswood, N.J. (https://www.yelp.com/biz/vagabond-philadelphia, 10/17/17)

"Oh man...." Katya heard Sarah mutter. "What?? What is it?" asked Katya. Sarah was scrolling through a Yelp page on the computer. "Now this is just harsh," answered Sarah. Katya promptly walked over to the computer screen to look over Sarah's shoulder to see one of the new Yelp reviews. A second review they looked at was even more derogatory.

If I could give this shop zero stars I would...rudest sales people ever...act as if customers are invisible...also having just moved to Philly from LA and San Francisco, I thought it might be fun to try shopping local.....wow...did I say most mention the most self-absorbed sales attitude ever? P.S you might want to back that attitude up with some cutting edge merchandise...how depressing that you actually think your backwater inventory is well curated or interesting...you must not travel much. Lisa W. Los Angeles, Ca. (https://www.yelp.com/biz/vagabond-philadelphia, 10/17/17)

"Wow, this woman did not hold back," muttered Katya as she perused the most recent comment. The commenter in question used some derogatory comments regarding the sales girls, and mentioned the girls having a "selfabsorbed sales attitude." The next post was no better.

I felt like I was in a scene from mean girls. The two ladies working at the store couldn't have been more rude and "judgey". Sorry but I shouldn't feel like I just walked into a party I wasn't invited to when going shopping with my money! No one offered to help and while some of the selection was nice, everything seemed to be way overpriced. I also bought a shirt that was on sale that was CLEARLY marked up before marking down. Literally, it had $\$ 89$ scribbled out followed by $\$ 110 \& 40 \%$ off. If you're going to rip people off at least be nice. Laura B. Philadelphia, Pa. (https://www.yelp.com/biz/vagabond-philadelphia, 10/17/17)

Another comment mentioned, "it seems as if the ladies here get paid to sit around chatting and ignoring customers. Decent inventory, not worth it considering the unwelcoming atmosphere." The girls looked at each other with wide eyes. "Wow," Sarah found herself stating simply. "Yeah," answered Katya. After a long pause Sarah added, "Well you can't keep everyone happy I suppose." The girls shrugged it off and resumed with their day. 


\section{APPENDIX A}

The Unique Interior of the Boutique

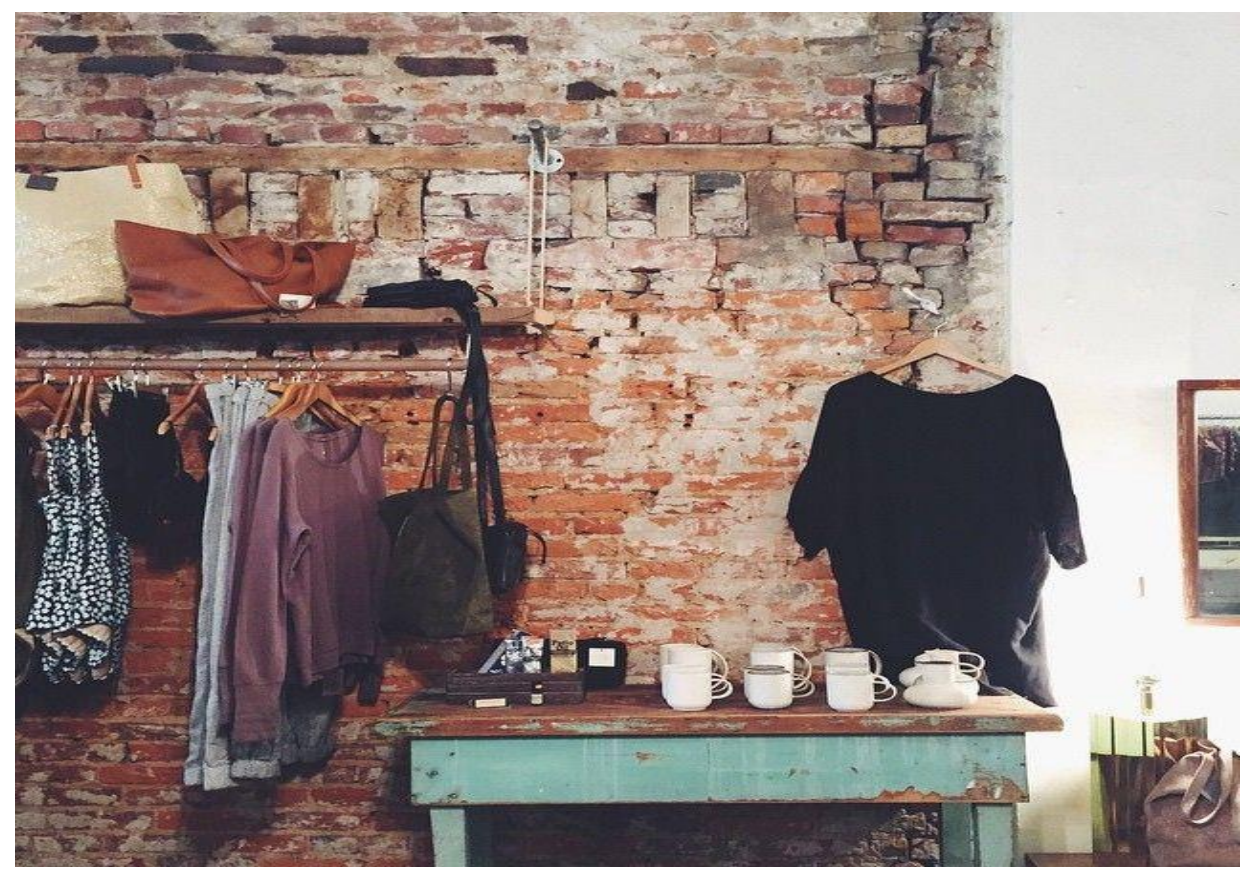

\section{Appendix B}

Vagabond Boutique Organizational Chart

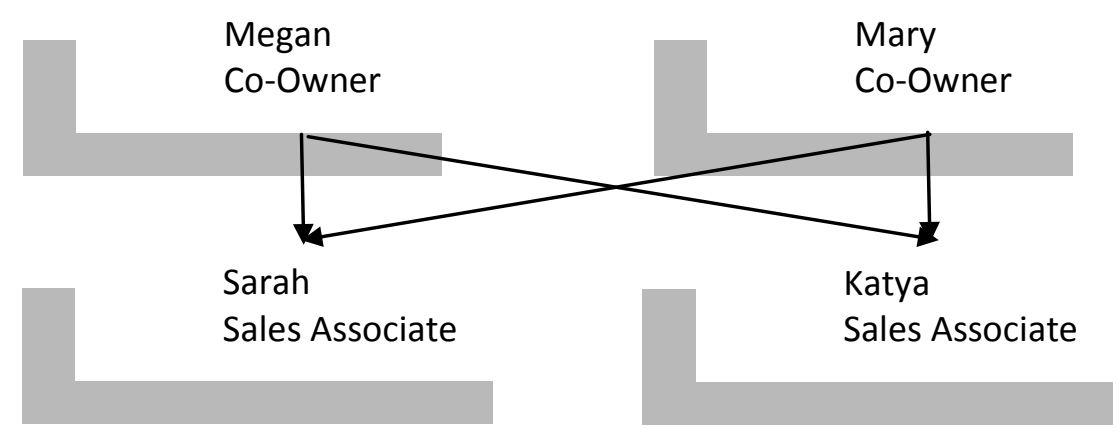

\section{Modified Instructional Note}

\section{Problem Statement/Applying Theory to Practice}

The lax attitude of the owners and employees manifested into extremely poor sales service that in turn resulted in extraordinarily negative reviews on the Yelp website. In many of the reviews, customers mentioned that the clothing was worth examining, yet, after experiencing extremely poor customer service, opted to leave the store. Some customers were so frustrated by their experience that they went so far as to write scathing Yelp reviews. The website Yelp is a powerful platform for smaller businesses, and such negative reviews can be exceptionally detrimental for the reputation, positioning and overall brand equity for such a business. (Rudolph, 2015)

In order to rectify this problem, the employees and the owners must work to modify their behavior to better suit the needs of their customers, and therefore create a service that will adequately represent the firm and its quality brand image. Although the boutique carries a unique variation of sought-after designer pieces, along with a respectable vintage collection, these factors did not suffice in satisfying their potential customers, who were negatively affectedby the poor service they received. 
In order to turnaround the negative Yelp reviews that Vagabond Boutique has been receiving, three concepts will be explored in as a means to alleviate this problem; brand differentiation, internal marketing, and service quality.

\section{Brand Differentiation}

The first theory to be applied is that of brand differentiation. Within a marketing context, brand differentiation is a paramount concept for a brand to achieve, in order to create a competitive advantage for itself and rise above its competitive landscape. Brand differentiation may be accomplished through several venues, be it by way of providing a unique product, price, collateral, or service experience. (Carter, 2014)

Vagabond Boutique is located on a cobble-stoned street, in a historic section of Philadelphia that is overrun by tourists on the weekends. The street is filled with various boutiques that offer a selection of products similar to that of Vagabond's. It is therefore vital for the boutique to differentiate itself from these other shops. One way in which the store can obtain a competitive advantage is through a quality service experience for their shoppers. When offering a similar product at comparable prices, the services provided can aid in successfully differentiating a store from several others.

Case in point. Apple is a brand that has successfully demonstrated superior quality service. Apple introduced its first retail store in Tokyo in 2002 at a time when retail stores were in decline, and still are (Bajarin, 2012). Customers if they were shopping retail, rather than on-line, were opting to go to big-box stores such as Walmart or Costco, where they could buy electronics at low prices or going to category killers that offered multiple bands like Best Buy where they would be served by their "Geek Squad". (Anonymous, n.d.) The idea of opening up a producer-based tech retail store seemed crazy to most consumers yet Apple found great success with this avenue. By introducing a service strategy that allowed employees to know closely each of the products, and to work closely with customers, the sales associates quickly and effectively helped customers with allof their concerns (Bajarin, 2012). The immense success of the services provided at the stores afforded the company a platform to differentiate themselves from other technological brands and multi-brand retail outlets.

\section{Internal Marketing}

The next theory that will be described and applied is that of internal marketing. Simply put, internal marketing is the process of "training and motivating employees to serve customers well" (Kotler, Lane, and Keller, 2016, p. 443). More importantly, internal marketing offers employees a more personal connection with what they are selling, which they can then effectively communicate to potential customers (Mitchell, 2002). As there is essentially no employee training offered at the boutique, nor do incentives for employees to better serve their customers, therefore internal marketing will prove to be an efficient means of improving the services sector of the boutique.

When internal marketing is correctly utilized, an emotional connection between the brand and the employee is formed. Research published by the Harvard Business Review found that when employees genuinely care for a brand [or a store in this case], they are more likely to be motivated to work harder, and are united by a notion of a common purpose (Mitchell, 2002).

Case in point.A brand that exemplifies the successful implementation of internal marketing is that of BP. British Petroleum grabbed hold of a pivotal moment for the company in order to rebrand itself among not only its customers, but also employees. When merging with Amoco and ARCO, the company renamed itself BP, standing for "beyond petroleum" (Mitchell, 2002). Additionally, the company shed its old skin as an oil company, to reveal its new identity as an energy company. Accompanying the brand's transformation was that of a metamorphosis for most employees - they were part of a new firm with a new culture. This change and successful implementation of internal marketing resulted in renewed attitudes and motivations among employees, as " $76 \%$ of employees felt favorably toward the new brand, $80 \%$ were aware of the brand values that constituted the new brand messages", both of which are paramount in producing successful service (Mitchell, 2002, p.1).

\section{Service Quality}

Finally, service quality is examinedthrough the findings of researchers Berry, Parasuraman, and Zeithaml(1985). Their findings suggest that there are 10 factors to examine when trying to improve service quality:

\section{Listening \\ 2.Reliability \\ 3.Basic service}




\section{Service design \\ 5.Recovery \\ 6.Surprising customers \\ 7.Fair play \\ 8.Teamwork \\ 9.Employee research \\ 10. Servant leadership}

Three of these factors will be examined in relation to Vagabond; servant leadership, service design, and recovery. The underlying theory behind servant leadership posits that quality service stems from quality leadership- it is a mentality that the needs of your employees come first and even before the needs of the customer (Kotler, Lane, \& Keller, 2016). This lesson additionally suggests that service quality stems from an outstanding service-system design; from the effective use of information and technology; and from a slow-to-change, invisible, all-powerful, internal force called corporate culture (Kotler and Keller, 2016). As evidenced by the Vagabond Boutique case, none of these elements was present within the firm, therefore stifling service quality.

Servant Leadership. One corporation that has successfully implemented the servant leadership mentality is that of Starbucks. The coffee corporation is renowned for its employee engagement and quality customer service, which reflects the successful application of the servant leadership paradigm. Howard Behar, who acted as company president of Starbucks and worked with Howard Schulz in transforming the coffeehouse to a national chain, described the need for employee engagement in creating a successful venture (Anonymous, 2015).

Behar explained that the most important thing leaders can do is live, eat and breathe whatever culture they want and then constantly reinforce and communicate their key values with their employees (Anonymous, 2015). Alternatively, to paraphrase Peter Drucker, culture eats strategy for breakfast. (Anders, 2016)

Service Design. In recent years, many brands offering products have introduced the concept of a product-service experience as a means to differentiate themselves from other brands (Bacon, 2104). A service design must therefore be implemented in order to ensure that all aspects of the service meet customers' needs (Bacon, 2014). An example of a brand that inculcated such a plan is Adidas, which launched the Home Court service design at their flagship store in Beijing. The concept allowed consumers to be fully immersed in the brand, with the flagship store being transformed into a sports arena (Bacon, 2014). The concept allowed customers to have a one of a kind experience in the shop and create brand "feelings", therefore creating a competitive advantage for Adidas relative to their competitors.

Recovery. Lastly, the recovery element is pivotal in improving service quality. If a customer is unhappy with the service they were provided, it is essential that the institution that had dispensed the service do everything in their power to rectify the situation. As described in the research of Berry, Parasurman, and Zeithaml, service companies should encourage customers to complain, respond quickly and personally, and develop a problemresolution system (Kotler, Lane, \& Keller, 2016). Recovery is paramount for brands as a bad service experience may lead to a customer switching brands and negative word of mouth (Michel, Bowen, \& Johnston, 2006). Therefore, the execution of a successful recovery is essential to accomplish as it positively influences customer satisfaction, word-of-mouth behavior, customer loyalty, and, eventually, customer profitability (Michel, Bowen, \& Johnston, 2006).

\section{Alternatives/Solution Strategy}

Based on the research of this case analysis, the theory that will be utilized to alleviate the issue of the bad Yelp reviews is that of the 10 lessons for improving service quality. For a small business, negative word of mouth may prove to be devastating and it is therefore paramount to tackle this issue from all points. For the purpose of this case analysis, three lessons will be examined in-depth in order to improve upon the service of the boutique, as well as to amend mistakes made in the past and retain customers.

Service Design. As illustrated in the case study, the sales service of the employees was incredibly poor stemming from the fact that there is no employee training offered to the sales staff, nor a service design of any sort. The owners of the boutique opted to wholeheartedly focus on the products offered in the boutique, rather than utilize a holistic approach that would emphasize all branches of the business. Customers therefore experienced several service encounter failures, such as unresponsiveness, impoliteness, and limited knowledge from the sales staff. A careful service design must be implemented in order to limit future service failures. 
As opposed to the complex and interactive design of the Adidas HomeCourt, Vagabond will simply create a service design that will limit customer service failures. With the careful implementation of such a design, new sales staff will be carefully trained. They will be expected to be knowledgeable of the products and to truly believe and enact the mission of Vagabond Boutique. The key values will be better expressed to all employees and a culture of openness and better communication will be implemented.

Servant Leadership. Another important point mentioned within the case study is that of the constant absence of the owners, Megan, and Mary. With no one present to utilize the hierarchical power of the owners, the sales staff is left to their own devices to perform their jobs without accountability and without a worry of repercussions. This in turn has made the sales staff lazy and impassive as to whether or not they provide a comfortable service environment. By following the lesson of servant leadership, it will be necessary for the owners of the boutique to create a culture of openness and utmost service in order to improve upon the "attitudes" that were perceived by many disgruntled customers, and to instill mindfulness within the employees. This will require hands-on management of the store including role modeling the behaviors that the owners want their employees to exhibit.

Recovery is the final step necessary for Vagabond Boutique. Customer dissatisfaction may occur at any point, and is therefore necessary to address as well as amend in order to retain customers. The main form of customers voicing their dissatisfaction with this service occurs on the Yelp platform. Many brands opt to quickly address the issue in an effort to empathize with the customer, recognize the firm's wrongdoing and amend the situation (Michel, Bowen, \& Johnston, 2006).

TN Figure 1 illustrates a correctly executed recovery tactic by way of responding to a negative Yelp review. The owner responded with fairness and empathy, and promised to rectify the situation by correcting the service quality.

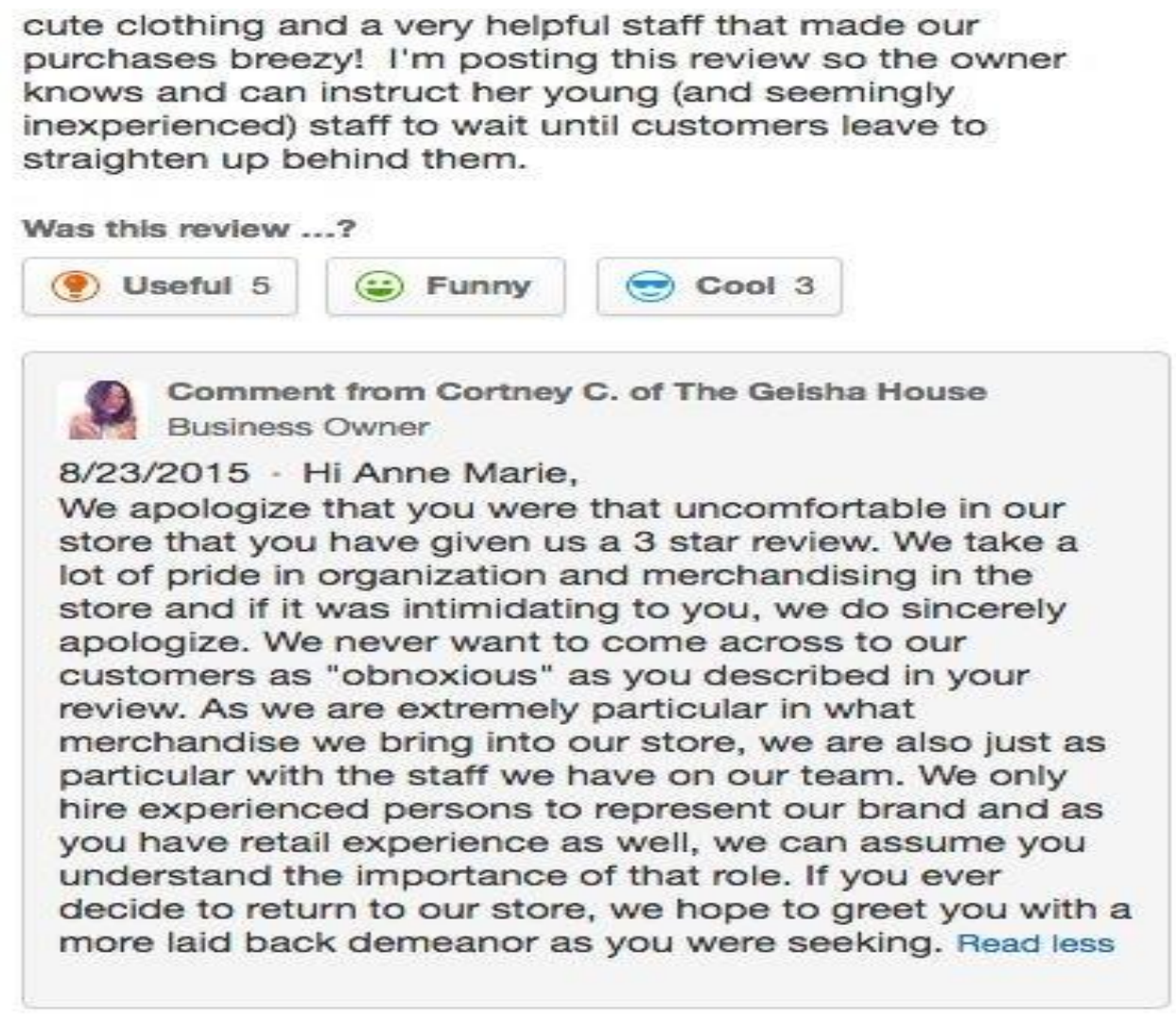

\section{TN Figure 1}

In contrast, Vagabond Boutique has never responded to the multitude of Yelp reviews posted in the case study. It would therefore be a sage action to quickly respond to the variety of reviews in an effort to spread positive wordof-mouth amongst customers, as well as to ensure the return of a dissatisfied customer and to then increase customer loyalty (Michel, Bowen, \& Johnston, 2006). In an effort to entice the dissatisfied customer in returning, the strategic implementation of offering the customer $10 \%$ off an item in stores may be utilized. 
With the implementation of these three elements of service quality, the services offered in the boutique will improve greatly and therefore combat future negative Yelp reviews.

\section{Conclusions}

On the surface, a few negative Yelp reviews seems like a very fixable problem, In writing this analysis, however, the reviews revealed much more deep-seated problems than might have been expected. The absence of a hierarchy of power, daily goals and sales incentives, as well as an antiquated inventory system have each individually contributed to the larger issue of poor service quality (hence several negative Yelp reviews). Such unintentional negative marketing has marred the image of the small boutique and diminished the brand's equity and positioning. The boutique's collection seems sought after, with customers oftentimes from New York traveling over 150 miles to Philadelphia for the brands the boutique carries. Yet, as evidenced by the several Yelp reviews, the most beautiful of vintage Versace jackets could not sway several of the customers to go back into the boutique due to the poor service they experienced. It was therefore interesting to recognize just how important the services are within the realm of marketing, and effectively creating a competitive advantage for the store name by way of a product-service experience. This seems profoundly correct within the operating realm of small businesses.

Concerning the three theories utilized within this analysis, the authors believe the most interesting one was that of internal marketing. Through field research, it was found that this is an element that is not always correctly implemented within a firm. The absence of such an aspect within a company is perplexing, as empirical research has found that such theory implementation often yields higher employee engagement. Instilling a passion for the company's mission within employees translates into a better customer shopping experience consistent with what the company promised through their corporate branding (Mitchell, 2002). Lastly, this case study illustrated just how important it is to recognize the importance of a customer's experience, and to be receptive of the needs and wants of a consumer in order to succeed in the world of small business.

\section{References}

Anders, G. (March 27, 2016). Did Peter Drucker actually say, "culture eats strategy for breakfast" - and if so, where/when? Retrieved from https://www.quora.com/Did-Peter-Drucker-actually-say-culture-eatsstrategy-for-breakfast-and-if-so-where-when, November 11, 2017.

Anonymous (n.d.) Geek Squad Services. Retrieved from https://www.bestbuy.com/site/electronics/geeksquad/pcmcat138100050018.c?id=pcmcat138100050018, October 31, 2017.

Anonymous (n.d.). What is internal marketing? Retrieved from https://www.reference.com/businessfinance/internal-marketing-c487b671a30b9a54,December 4, 2016.

Anonymous (2015). How Starbucks Built a Servant Leadership Culture: Q\&A With Howard Behar - Greenleaf Center for Servant Leadership. Retrieved from https://www.greenleaf.org/how-starbucks-built-a-servantleadership-culture-qa-with-how ard-behar/, December 4, 2016.

Bajarin, T. (2012). 6 Reasons Why Apple Is Successful. Retrieved, from http://techland.time.com/2012/05/07/sixreasons-why-apple-is-successful/,December 4, 2016.

Bacon, J. (2014). Service design is revolutionising retail - Marketing Week. Retrieved from

https://www.marketingweek.com/2014/05/28/service-design-is-revolutionising-retail/, December 4, 2016,

Carter, L. (2016). Brand Differentiation: 30 Ways to Differentiate Your Brand - Persona Design. Retrieved from http://www.personadesign.ie/brand-differentiation-30-ways-to-differentiate-your-brand/,December 4, 2016.

Kotler, P. T. and K. L. Keller (2016). Marketing Management. $16^{\text {th }}$ Ed. New York: Pearson.

Michel, S., Bowen, D. E., \& Johnston, R. (2009). Why service recovery fails: Tensions among customer, employee, and process perspectives. Journal of Service Management, 20, 253-273.

Mitchell, C. (2002). Selling the Brand Inside. Retrieved from https://hbr.org/2002/01/selling-the-brandinside,December 4, 2016.

Parasuraman, A., Zeithaml, V.A. and Berry, L.L. (1985). A conceptual model of service quality and its implications for future research.Journal of Marketing, 49, 3, 41-50.

Rudolph, S. (July 25, 2015). The Impact of Online Reviews on Customers' Buying Decisions. Infographics. Retrieved from http://www.business2community.com/infographics/impact-online-reviews-customersbuying-decisions-infographic-01280945\#s3eShJW0RZqQIUfD.99, October 31, 2017. 